\title{
O trânsito \\ expressa o uso do espaço urbano
}

A psicóloga Maya Hantower, coordenadora do Núcleo de Estudos e Pesquisas do Comportamento, da Companhia de Engenharia de Tráfego - CET (órgão que presta serviços d Secretaria Municipal de Transportes de São Paulo), considera que a atuação do psicólogo na questão do trânsito deve estar voltada para a reduç̃o dos altos índices de acidentes no trânsito, hoje.

Por ser um problema bastante complexo, o psicólogo deve trabalhar em equipes multiprofissionais, produzindo pesquisas para obter uma visão integrada da situação atual do trânsito no Brasil e poder elaborar dados que contribuam com os planos de ação a serem postos em prática pelos órgãos públicos.

Aqui está o que nos relatou Maya Hantower:

"No Brasil, constatou-se que cerca de $50 \%$ de mortes fatais nos acidentes de trânsito são resultado de atropelamento de pedestres. No $\mathrm{Mu}$ nicípio de São Paulo, essa percentagem aumenta e atinge cerca de $60 \%$. Tais índices retratam apenas os atropelamentos, sem contar os outros tipos de acidentes fatais.

Quem são esses pedestres atingidos por atropelamentos? Temos uma idéia de que a maioria deles, são pessoas de baixa renda, embora esse dado não tenha sido confirmado ainda por pesquisas sistemáticas. Estas pessoas não estão aculturadas no meio urbano e acabam sendo atropeladas nos corredores de trânsito que podem ser os locais de grande fluxo de veículos tanto do centro quanto da periferia das grandes cidades.

Pedestres versus motoristas

O trânsito é uma atividade que está profundamente articulada ao sistema sócio-econômico de uma cidade.

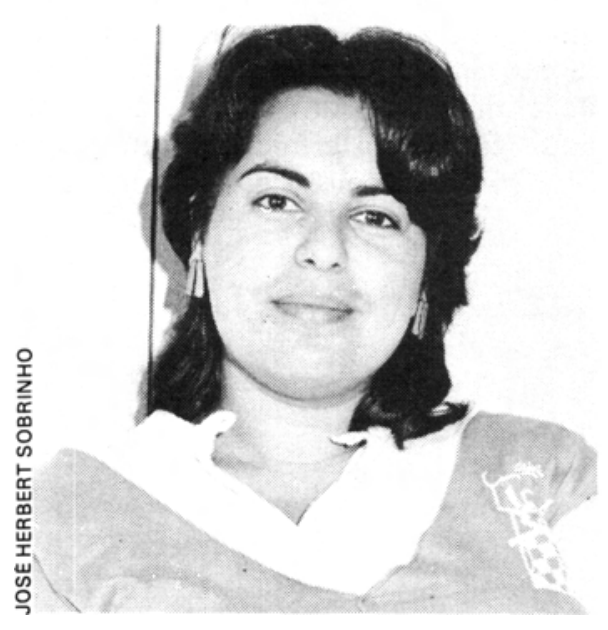

Num país terceiro-mundista, como é o caso do Brasil, o trânsito expressa uma profunda desigualdade na apropriação do espaço urbano, refletindo o conflito entre pedestres e condutores de veículos. Nesse conflito, o pedestre costuma ser o grande prejudicado, pois o tráfego de veículos é privilegiado em detrimento do tráfego dos pedestres.

Os atropelamentos de pedestres revelam um problema social. Na periferia de grandes cidades como São Paulo, existem as vias, que antes ligavam os municípios vizinhos, mas hoje estão ocupadas com casas construídas em ambos os lados dessas vias, e o tráfego de veículos continuou intenso e em alta velocidade. Os moradores são obrigados a atravessar essas vias cotidianamente. A população local sente a ação dos órgãos públicos como distante e inacessível, perdendo a esperança de que estes órgãos possam intervir de maneira a resolver o problema.

Nesses locais, ocorreram muitos quebra-quebras em função de atropelamentos frequentes de crianças. Os moradores tomam a iniciativa por conta própria: quebram o asfalto, abrem uma valeta e impedem o fluxo dos veículos. É um movimento espontâneo, desesperado, de forte conteúdo emocional.

\section{Os psicotécnicos não diminuem os acidentes}

A antiga idéia do teste psicotécnico se baseia na existência de motoristas com características de personalidade propensas a provocarem acidentes. O psicotécnico seria o instrumento para detectar os motoristas acidentógenos no conjunto dos motoristas e retirá-los do trânsito. Em última instância, o psicotécnico existiria para que houvesse a menor possibilidade de acidente no trânsito.

Os psicotécnicos não estão dando conta adequadamente do problema por duas razões. Em primeiro lugar, estes instrumentos não estão validados para a população brasileira. Em segundo lugar, as pesquisas feitas em outros países demonstraram que não há uma diferença significativa entre uma população de motoristas que havia e uma outra que não havia se envolvido em acidentes. A partir dai, houve um avanço das reflexões a respeito dessa questão, de tal modo que deixaram de usar o psicotécnico para selecionar os motoristas.

Nesses países, fortaleceu-se então a preparação do motorista para a habilitação e, simultaneamente, criaram-se programas de incentivo para quem não tivesse se envolvido em acidentes ou infrações. No Canadá, por exemplo, motoristas, que não tinham recebido multas durante um certo período de tempo, recebiam como premiação uma redução na sua taxa anual de licença para trafegar. $\dot{E}$ uma tentativa de sair do sistema punitivo, criando uma forma de estimular - comportamento adequado no trânsito. 


\section{A valorização do psicólogo no trânsito}

Estou convencida de que qualquer atividade que o psicólogo desenvolva com relação à problemática do trânsito deve ter como pano de fundo os acidentes-que matam muito mais do que se constuma imaginar - e, como objetivo, a redução desses acidentes.

A garantia da valorização do trabalho do psicólogo no trânsito é a pertinência e a importância social deste trabalho. Como o psicólogo poderia atingir esse objetivo? Por exemplo, nada conhecemos a respeito do perfil psico-social dos motoristas e pedestres brasileiros envolvidos nos acidentes. $O$ psicólogo pode produzir dados de pesquisas através do registro e da análise dos comportamentos de motoristas e de pedestres. Neste aspecto, coloca-se inclusive um desafio no campo metodológico de pesquisa, na medida em que não temos técnicas criadas e adaptadas para a situação de trânsito no Brasil.

\section{A formação e as oportunidades de trabalho}

Existe uma falta de informação muito grande a respeito dessa área de atuação, entre os próprios psicólogos. Os futuros psicólogos têm um contato com a Psicologia do Trânsito restrito à aprendizagem de três ou quatro testes psicotécnicos. Dessa maneira, os futuros psicólogos não têm preparação teórica e prática para poderem vir a trabalhar nesta área. Poderia ser feita a proposta de criar a cadeira de Psicologia do Trânsito nos cursos de graduação, mas não haveria professores já preparados que viessem a formar os alunos para trabalharem nessa área.

$\mathrm{Na}$ situação atual, o psicólogo precisa criar a coragem para transformar as suas atividades adotadas nessas áreas. Há uma boa parte de psicólogos que trabalha com psicotécnico e que apresenta dúvidas ou questões a respeito do seu trabalho. Por isso, é preciso assumir que há esse questionamento, começando a pensar em propostas alternativas.

Na minha opinião, a contribuição do psicólogo na melhoria do trânsito deveria começar por criar um programa básico de preparação para habilitação que abarque desde o conhecimento das habilidades psicomotoras envolvidas no ato de dirigir um veícu- lo até a questão do treinamento e da sensibilização para a segurança no trânsito. Nesse tipo de programa, a atuação do psicólogo é múltipla: supervisionar os monitores das autoescolas, estudar as formas de conferir o conhecimento adquirido pelos motoristas, tratar de casos-problema que apresentem dificuldades emocionais etc.

Além disso, o psicólogo pode colaborar também em programas destinados a quem já está habilitado, mas apresenta recorrentemente comportamentos inadequados no trânsito. Desde o momento da preparação e da aquisição da carteira de habilitação, é preciso criar meios de o motorista se conscientizar de que, com a carteira de habilitação, adquire um direito e ao mesmo tempo adquire deveres.

\section{Como melhorar o trânsito?}

Para melhorar o trânsito, os especialistas costumam apontar a necessidade de se atuar em três esferas de trabalho: educação, engenharia e fiscalização. A educação envolve a formação de diversos tipos de usuários, incluindo-se as crianças. A engenharia é responsável pelo projeto das vias, cálculo do tempo samafórico, sinalização etc. A fiscalização fica a cargo da polícia que procura fazer

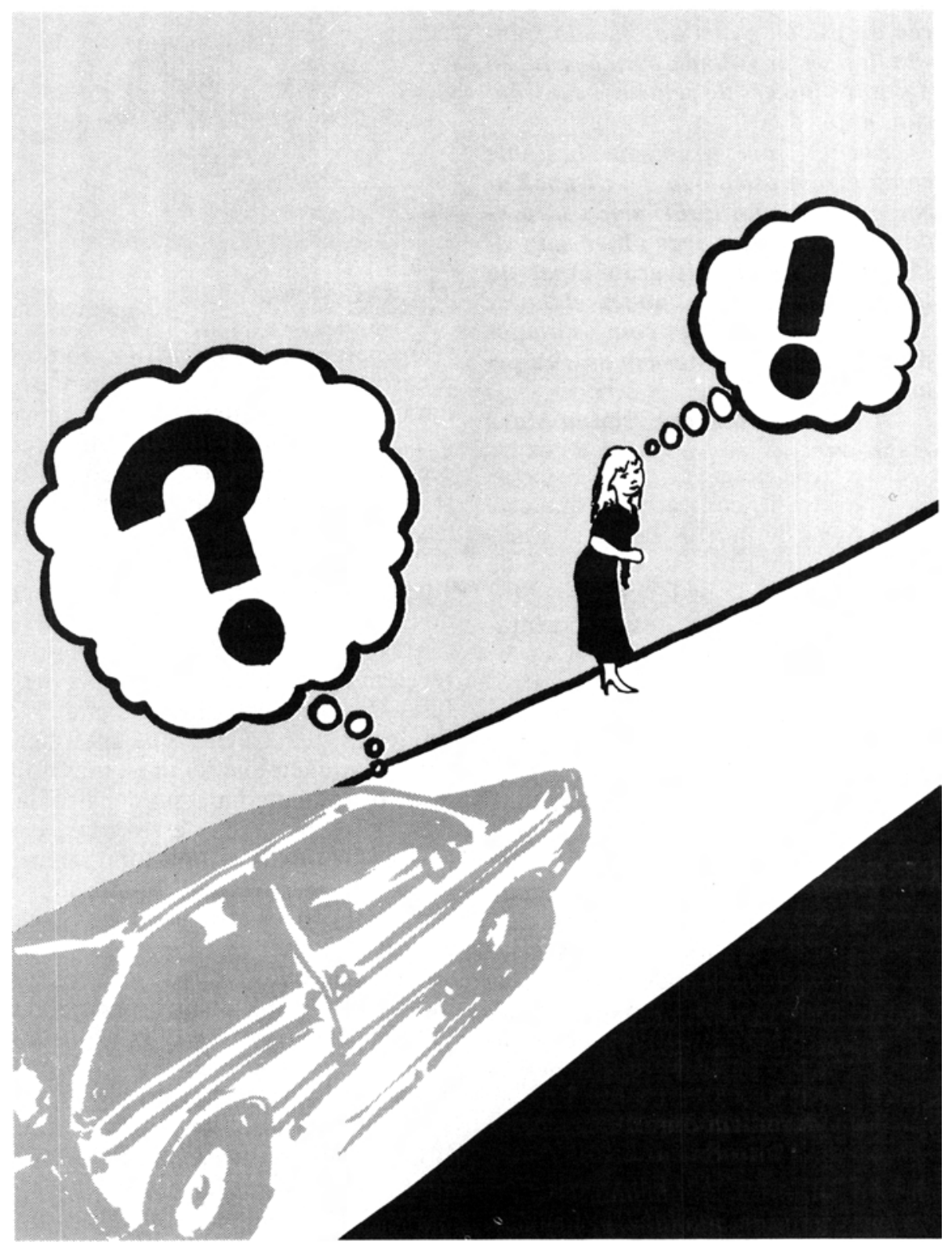



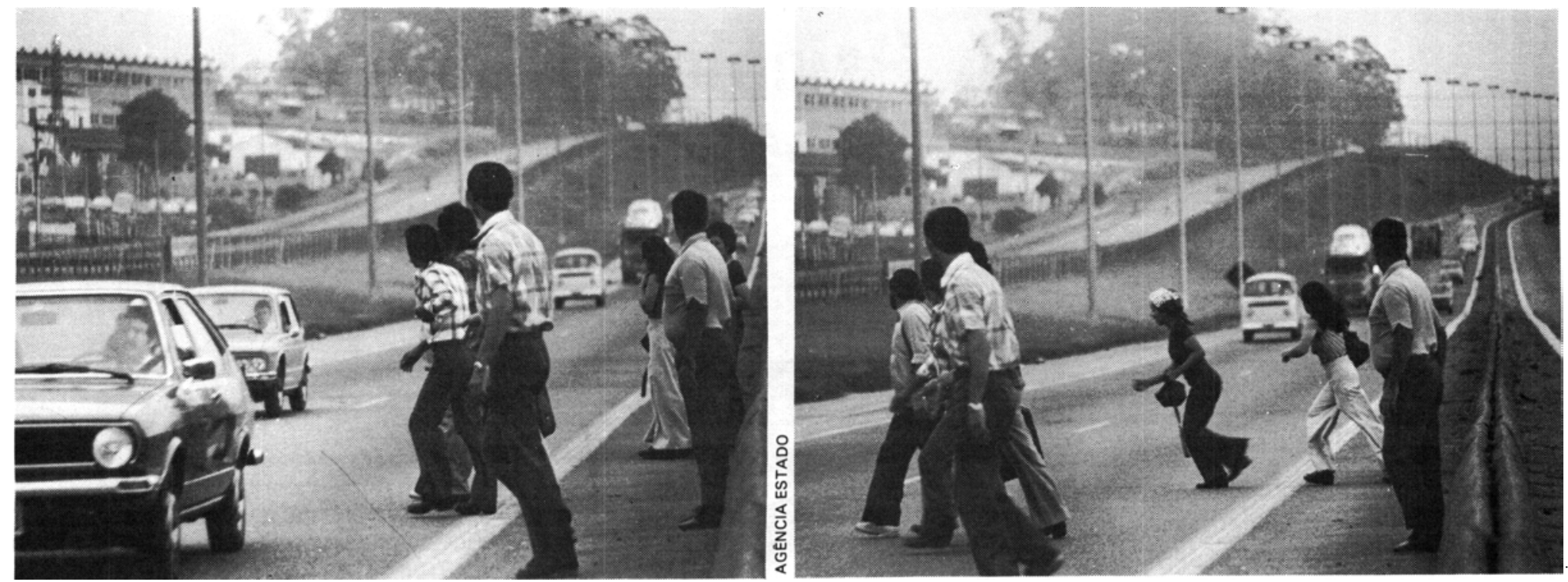

com que o Código Nacional de Trânsito seja respeitado pelos usuários.

Dentro desta orientação, a Companhia de Engenharia de Tráfego possui um Núcleo de Estudos e Pesquisas do Comportamento, sendo o único órgão público ligado ao trânsito que mantem atividades de pesquisa própria. Embora ainda esteja limitado em termos de recursos e pessoal, já é um avanço, pois reconheceu a importância da produção de pesquisas e da presença do psicólogo em prol da redução de acidentes. $O$ trânsito costuma ser visto pelos órgãos públicos ligados a esse setor como uma questão exclusiva de engenharia de tráfego. Só recentemente está havendo uma maior valorização das Ciências Humanas nesses órgãos públicos. Aos poucos, começa a ser reconhecida a importância de cientistas sociais, psicólogos, pedagogos etc., que trabalham e pesquisam juntos com outros técnicos, para possibilitar uma visão integrada e dar conta do trânsito como um todo.

Atualmente, realizamos no Núcleo de Estudos da CET uma extensa pesquisa bibliográfica sobre 0 comportamento no trânsito para conhecer o que já foi produzido em outros países e assim subsidiarmos nossas atividades. Em termos de desenvolvimento de pesquisas, temos duas em andamento: uma delas refere-se ao nivel de compreensão da sinalização dê a preferência e a outra envolve uma experiência com relação à antecipação de semáforo. Na primeira pesquisa, estamos tentando verificar se o motorista compreende o significado da placa dê a preferência, em três níveis: 1) qual é a decodificação da mensagem feita pelo motorista; 2) qual é o comportamento do motorista quando vê essa placa; 3) qual é o nível de consciência de risco, ou seja, se o motorista não fizer o que a placa indi$\mathrm{ca}, \mathrm{o}$ que supõe que pode lhe acontecer? Se nós comprovarmos que há um número significativo de motoristas que não sabe qual é o significado da placa, estudaremos a possibilidade de anexar-lhe uma legenda. Numa segunda etapa, pesquisaremos qual é a forma de apreensão visual da placa munida de legenda. Finalmente, faremos uma pesquisa, em determinados locais, para verificar se a colocação da legenda na placa implicou uma diminuição de acidentes nesses locais.

A segunda pesquisa que estamos desenvolvendo é a da antecipação de semáforo, colocando-o antes do cruzamento de ruas. Nesse caso, o motorista que quiser ultrapassar o sinal vermelho vai correr um risco bem maior na medida em que ele vê o semáforo, mas não vê, ou vê, com mais dificuldade o carro vindo na rua transversal, ou vice-versa. Por outro lado, a antecipação do semáforo obriga o motorista a respeitar a faixa de pedestres, que tem o status de continuação da calçada, pois se ele invade a faixa com o veículo não vê mais o semáforo que ficou para trás dele. A nossa hipótese é que a antecipação do semáforo aumenta a margem de risco do motorista e pode inibir comportamentos inadequados. Ao fazermos mudanças físicas na geometria do espaço do trânsito, podemos conseguir mudanças de comportamento. Essa experiência foi feita em São Paulo num cruzamento de ruas que era um dos mais perigosos da cidade. Houve um decréscimo significativo dos acidentes com vitimas, nesse cruzamento.

\section{As atribuições do Estado}

O Estado deve tomar para si a tarefa de incentivar os centros de pesquisa que vão produzir dados sobre a realidade do trânsito no País. Vou dar um exemplo de um país primeiromundista, a França. Lá o índice de acidentes estava aumentando a cada dia. Criou-se a Organização Nacional de Segurança Viária, um órgão interministerial encarregado de desenvolver pesquisas sobre trânsito. Nele, atuavam equipes multiprofissionais que produziram dados sobre a realidade do trânsito e que serviram para informar as diretrizes de atuação dos diversos órgãos públicos ligados ao trânsito. A partir daí, começou a haver um decréscimo nos índices de acidentes.

O Estado não assumiu, mas deve assumir estas atribuições $e$, para tanto, é importante ocorrer a manifestação de entidades, dos sociólogos,engenheiros, economistas, psicólogos, educadores etc.,bem como da população em geral. Estas diferentes entidades devem pronunciar-se a respeito dos acidentes do trânsito como um grave problema social, assumindo que a minoração dos acidentes depende basicamente de planos de ação integrados. 